\title{
Inter Observer Variability in the Specificity of Magnetic Resonance Imaging for External Impingement of the Shoulder-Is There Agreement among Radiologists?
}

\author{
N. Baraza, K. Goswam, S. A. Shahban \\ Heartlands Hospital, Birmingham, UK \\ Email:shafiqshahban@hotmail.com
}

How to cite this paper: Baraza, N., Goswam, K. and Shahban, S.A. (2017) Inter Observer Variability in the Specificity of Magnetic Resonance Imaging for External Impingement of the Shoulder-Is There Agreement among Radiologists? Open Access Library Journal, 4: e3472.

https://doi.org/10.4236/oalib.1103472

Received: February 21, 2017

Accepted: April 24, 2017

Published: April 27, 2017

Copyright ( $\odot 2017$ by authors and Open Access Library Inc.

This work is licensed under the Creative Commons Attribution International License (CC BY 4.0).

http://creativecommons.org/licenses/by/4.0/

\begin{abstract}
Purpose: External impingement in the shoulder is a condition characterised by tenderness in the antero-lateral aspect of the shoulder on arm elevation due to an absolute or relative decrease in the subacromial space. Magnetic resonance imaging (MRI) is frequently utilised to confirm the condition and rule out other differential diagnoses. We conducted a study to look at the inter observer variability in specificity of MRI scanning in impingement of the shoulder. Methods: Twenty-six shoulders aged between 20 and 34 who all presented with shoulder instability only were included in the study. Three experienced consultant musculoskeletal radiologists were then asked to comment on the presence or absence of impingement on reviewing their MRI scans. Results: Radiologist 1 (R1) diagnosed 7 shoulders with impingement and 19 shoulders without. Radiologist 2 (R2) observed that 13 shoulders had radiological signs of impingement and 13 did not, and radiologist 3 (R3) suspected impingement in 20 shoulders with 6 shoulders normal. For R1 and R2, the agreement was 0.58 with a kappa value of 0.16 . Between R2 and R3, the agreement was also 0.58 with a kappa value of 0.16 . Comparing R1 and R3, the agreement was 0.46 and the kappa value was 0.14 . Across all three radiologists, there was agreement in 8 out of the 26 MRI scans (31\%) but only in 4 out of the $26(15.4 \%)$ did they all agree that impingement was not present. Conclusion: MRI should be used judiciously in the work up of patients with external impingement of the shoulder.
\end{abstract}

\section{Subject Areas}

Radiology \& Medical Imaging

\section{Keywords}

Shoulder Pain, Impingement, External Impingement, MRI Scanning in 
Shoulders, Shoulder Imaging, Specificity of MRI in External Impingement

\section{Introduction}

External impingement of the shoulder is a condition characterised by tenderness in the antero-lateral aspect of the shoulder on arm elevation due to an absolute or relative decrease in the space between the humeral head and the coraco-acromial arch. This space contains, from inferior to superior, the tendon of the long head of the biceps, the rotator cuff, the subacromial bursa, and the coracoacromial ligament. Pathology of any one of these structures or their bony boundaries, the head of the humerus or the acromion process can lead to impingement, a common cause of shoulder morbidity in the middle aged. The diagnosis is mainly clinically made after a history and examination, though increasingly MRI scanning is utilised to confirm the condition and rule out other differential diagnoses such as rotator cuff tears that may affect the treatment plan. We conducted a study to look at the specificity of MRI scanning in impingement of the shoulder and discuss the relevance of this imaging modality in aiding the clinician.

\section{Methods}

Twenty four patients, 21 males and 3 females, (26 shoulders) who all presented with shoulder instability only and no clinical signs of impingement were included in the study (Figure 1). They had all been assessed either directly by or under the supervision of a consultant shoulder orthopaedic surgeon. They had their MRI scans reviewed by 3 independent experienced consultant musculoskeletal radiologists who were blinded to the indications of the scans, patient age and the previous reports. We asked the radiologists to comment on whether or not impingement was present on the MRI images. The agreement between the three radiologists was then statistically determined.

\section{Results}

Radiologist 1 (R1) diagnosed 7 shoulders with impingement and 19 shoulders without. Radiologist 2 (R2) observed that 13 shoulders had radiological signs of

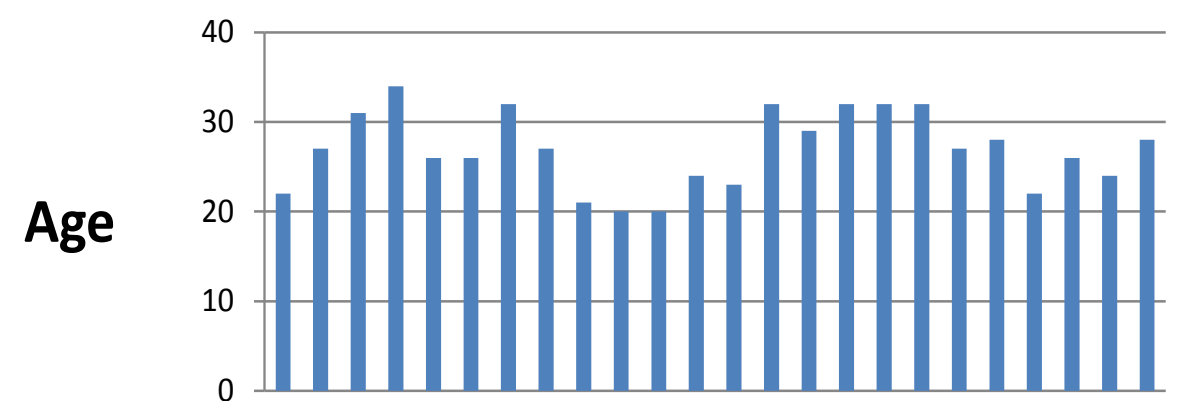

Figure 1. Age spread. 
impingement and 13 did not, and radiologist 3 (R3) suspected impingement in 20 shoulders with 6 shoulders normal (Figure 2).

\section{Statistical analysis}

In order to compare inter-rater variability, the kappa value is utilised. This figure is calculated by first finding out the agreement between the observers then factoring in the individual cases they agreed on and the possibility of this agreement being down the chance. This gives a kappa value between 0 and 1 , where 1 denotes perfect agreement and 0 demonstrates that the agreement was no better than chance. Landis and Koch [1] published guidelines on the adequacy of inter observer reliability and interpretation of the kappa value and is summarised in Table 1.

The agreement and kappa values of the study are summarised in Table 2. Across all three radiologists, there was agreement in 8 out of the 26 MRI scans (31\%) but only in 4 out of the $26(15.4 \%)$ did they all agree that impingement was not present.

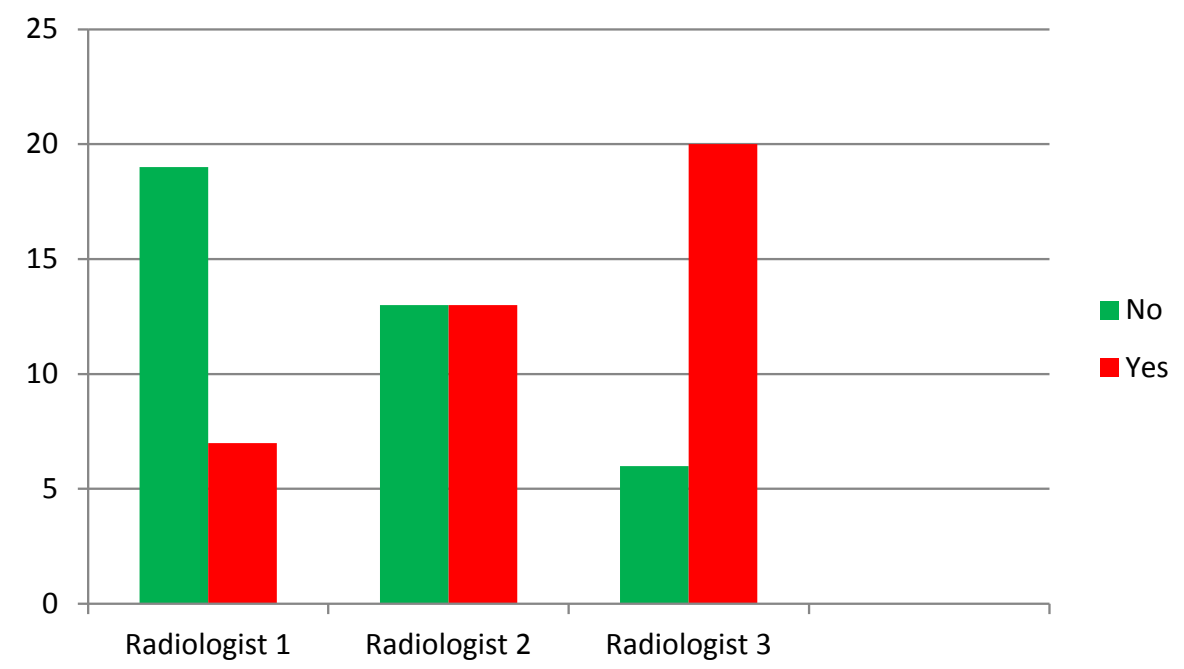

Figure 2. Bar chart of shoulders diagnosed with impingement by each radiologist.

Table 1. Landis and Koch table on interpretation of kappa values.

\begin{tabular}{cc}
\hline Kappa value & Classification \\
\hline$<0.20$ & Poor \\
$0.21-0.40$ & Weak \\
$0.41-0.60$ & Moderate \\
$0.61-0.80$ & Good \\
$0.81-1.00$ & Very good \\
\hline
\end{tabular}

Table 2. Agreement and kappa values across all 3 radiologists.

\begin{tabular}{rccc}
\hline & R1 vs. R2 & R2 vs. R3 & R1 vs. R3 \\
\hline Agreement & 0.58 & 0.58 & 0.46 \\
Kappa value & 0.16 & 0.16 & 0.14 \\
\hline
\end{tabular}




\section{Discussion}

External impingement occurs due to compression of the structures between the humeral head and the coraco-acromial arch on arm elevation. Clinically, provocative tests such as Neer's and Hawkin's are invaluable in making the diagnosis but recent studies have shown that Hawkins test may actually create internal impingement [2] -abutment of the articular surface of the rotator cuff between humeral head on the edge of the glenoid-and subacromial decompressions performed on patients with internal impingement will be of limited benefit. Furthermore, in the Neer's provocative position (full flexion in internal rotation) the space between the rotator cuff and the acromion was found to be increased [3]. This makes accurate clinical diagnosis challenging and often to aid the clinician imaging is utilised.

The use of MRI scans in picking up shoulder pathology is controversial. An early study by Ianotti et al. [4] showed a sensitivity of $100 \%$ and specificity of $95 \%$ for complete tears of the rotator cuff, and sensitivity of $87 \%$ and specificity of $93 \%$ for differentiation between normal and inflamed tendon. Nelson et al. [5] demonstrated the superiority of MRI in establishing the aetiology of a painful shoulder and with its superior soft tissue detail, Uri [6] reported that MRI was the favoured imaging tool in rotator cuff pathologies, a claim supported by Bachman et al. [7] who, in a cadaveric study, found MRI had a sensitivity of $96 \%$ and a specificity of $100 \%$ in differentiating between normal and abnormal cuff tendons. This was challenged by Torstensen et al. [8] who compared MRI to arthroscopic findings and reported a sensitivity of $96 \%$ but a lower specificity of $49 \%$ in picking rotator cuff tears.

On MRI, possible features of external impingement are a large amount of fluid within the subacromial bursa and medial to the acromioclavicular joint [9], a reduction in the acromiohumeral distance [10], the presence of downward facing acromioclavicular joint osteophytes [11], the shape of the acromion [12] [13] [14], an os acromiale [15] and rotator cuff lesions [16] [17]. However, many of the above lesions have been found in asymptomatic shoulders making radiological diagnosis unreliable.

In our study, the patients had MRI taken using a Toshiba ${ }^{\mathrm{TM}} 1.5$ Tesla scanner with $4 \mathrm{~mm}$ slices. On the axial $\mathrm{T} 2$ weighted views a field echo was applied with a repetition time (TR) of 551 milliseconds and an echo time (TE) of 15 milliseconds. The coronal T1 weighted images had a spin echo and a TR of $416 \mathrm{~ms}$ and a TE of $12 \mathrm{~ms}$. The T2 weighted coronal images had a TR of $3136 \mathrm{~ms}$ and a TE of $96 \mathrm{~ms}$. The coronal STIR images had a TR of $4483 \mathrm{~ms}$ and TE of $48 \mathrm{~ms}$. In the sagittal view, the TR was $3136 \mathrm{~ms}$ and the TE $96 \mathrm{~ms}$. All were sent to radiology because of instability and had a plain MRI as a first line of investigation prior to later having an MRI arthrogram if any doubts persisted as to the cause of their symptoms after a normal initial MRI. In this study, the radiologists were asked to comment on the MRI arthrogram. Though none had clinical signs of impingement, in several of the cases there were signals picked up by the radiologists that led them to believe that in the majority of patient's external impinge- 
ment was present.

There was very little agreement however amongst the three radiologists, as shown by the low kappa values $(<0.2)$. One possible explanation for this is the lack of standardised protocol for assessing impingement. The radiologists used the above parameters of external impingement in different measure to determine whether they thought impingement was present. Also, the limits of acceptable radiological signs will vary depending on training, previous experience and differing patient anatomy.

Another possible reason for variation in reporting of the MRI scans is that they were contrast pictures, as the initial clinical pathology in question was instability rather than impingement, and this may have interfered with the usual signal given off in the presence of cuff tendinopathy leading to a false positive. Only one radiologist of the three thought that this interfered with their ability to make a confident diagnosis. In addition to this, signal intensity is influenced by the orientation of tendon fibres relative to the magnetic field, which may lead to misdiagnosis of normal rotator cuffs [18].

There were a few limitations to our study which we fully acknowledge. Firstly, the acromio-humeral distance is dependent on gender and arm position, this distance in men being $1.2 \mathrm{~mm}$ more on average with the arm in $30^{\circ}$ abduction; and at $90^{\circ}$ this distance is reduced further in both sexes. In our study, there was no standardisation of arm position whilst patients were in the MRI scanner and slight variations in positions may have led to an increased chance of an erroneous report by the radiologists. Ideally, we would have also had in this study a cohort of patients who clinically had impingement and MRI scans to compare with the patients who were included in this study to establish the sensitivity of MRI in this series as well. In our unit though, patients who are clinically thought to have impingement do not routinely have MRI scans so it was not possible to make this comparison [19]. The radiologists taking part in the study were prone to reporting bias when asked to comment on whether impingement was present on the MRI scan. With this condition being one of the most common shoulder pathologies, they may have had a lower threshold of "diagnosing" it on the scan. Lastly, in this paper, the kappa values were used to determine inter-rater reliability. However, it has been shown that with small sample sizes the kappa values tend to be lower [20] so with a larger sample size the values may have differed.

\section{Conclusion}

External impingement is a largely clinical diagnosis, and this study has shown that MRI can be misleading. Moreover, there is little agreement even among experienced musculoskeletal radiologists regarding the possible appearance of lesions in the shoulder. For these reasons, clinicians should be judicious in the use of this imaging modality, and closer communication between surgeon and radiologist should be developed prior to and, if the MRI scan is performed, after imaging so that the most effective treatment plan can be instituted. In our experience, this imaging modality has the limited value in assisting the clinician 
when deciding whether or not patients require the operative treatment of this common condition.

\section{References}

[1] Landis, R.J. and Koch, G.G. (1977) The Measurement of Observer Agreement for Categorical Data. Biometrics, 33, 159-174. https://doi.org/10.2307/2529310

[2] Edelson, G. and Teitz, C. (2000) Internal Impingement in the Shoulder. Journal of Shoulder and Elbow Surgery, 9, 308-315. https://doi.org/10.1067/mse.2000.105449

[3] Roberts, C.S., Davila, J.N., Hushek, S.G., Tillett, E.D. and Corrigan, T.M. (2002) Magnetic Resonance Imaging Analysis of the Subacromial Space in the Impingement Sign Positions. Journal of Shoulder and Elbow Surgery, 11, 595-599. https://doi.org/10.1067/mse.2002.127095

[4] Ianotti, J.P., Zlatkin, M.B., Esterhai, J.L., Kressel, H.Y., Dalinka, M.K. and Spindler, K.P. (1991) Magnetic Resonance Imaging of the Shoulder. Sensitivity, Specificity and Predictive Value. Journal of Bone and Joint Surgery America, 73, 17-29. https://doi.org/10.2106/00004623-199173010-00004

[5] Nelson, M.C., Leather, G.P., Nirschl, R.P., Pettrone, F.A. and Freedman, M.T. (1991) Evaluation of the Painful Shoulder. A Prospective Comparison of MRI, Computerized Tomographic Arthrography, Ultrasonography and Operative Findings. Journal of Bone and Joint Surgery America, 73, 707-716. https://doi.org/10.2106/00004623-199173050-00009

[6] Uri, D.S. (1997) MR Imaging of Shoulder Impingement in Rotator Cuff Disease. Radiologic Clinics of North America, 35, 77-96.

[7] Bachman, G.F., Melzer, C., Heinrichs, C.M., Mohring, B. and Rominger, M.B. (1997) Diagnosis of Rotator Cuff Lesions: Comparison of US and MRI on 38 Joint Specimens. European Radiology, 7, 192-197. https://doi.org/10.1007/s003300050133

[8] Torstenten, T.C. and Hollinshead, R.M. (1999) Comparison of Magnetic Resonance Imaging and Arthroscopy in the Evaluation of Shoulder Pathology. Journal of Shoulder and Elbow Surgery, 8, 42-45. https://doi.org/10.1016/S1058-2746(99)90053-8

[9] White, E.A., Schweitzer, M.E. and Haims, A.H. (2006) Range of Normal and Abnormal Subacromial/Subdeltoid Bursa Fluid. Journal of Computer Assisted Tomography, 30, 316-320. https://doi.org/10.1097/00004728-200603000-00030

[10] Mayerhoefer, M.E., Breitenseher, M.J., Wurnig, C., et al. (2009) Shoulder Impingement: Relationship of Clinical Symptoms and Imaging Criteria. Clinical Journal of Sport Medicine, 19, 83-89. https://doi.org/10.1097/JSM.0b013e318198e2e3

[11] Cuomo, F., Kummer, F.J., Zuckerman, J.D., et al. (1998) The Influence of Acromioclavicular Joint Morphology on Rotator Cuff Tears. Journal of Shoulder and Elbow Surgery, 7, 555-559. https://doi.org/10.1016/S1058-2746(98)90000-3

[12] Neer, C.S. (1983) Impingement Lesions. Clinical Orthopaedics and Related Research, 173, 70-77.

[13] Bigliani, L.U. (1991) Impingement Syndrome: Etiology and Overview. In: Watson M.S., Ed., Surgical Disorders of the Shoulder, Churchill Livingstone, New York, 237-246.

[14] Bigliani, L.U., Morrison, D.S. and April, E.W. (1986) The Morphology of the Acromion and Its Relationship to Rotator Cuff Tears. Orthopaedic Transactions, 10, 228.

[15] Davlin, C.D. and Fluker, D. (2003) Bilateral Os Acromiale in a Division I Basketball Player. Journal of Sports Science and Medicine, 2, 175-179. 
[16] Sein, M.L., Walton, J., Linklater, J., et al. (2007) Reliability of MRI Assessment of Supraspinatus Tendinopathy. British Journal of Sports Medicine, 41, e9. https://doi.org/10.1136/bjsm.2006.034421

[17] Manvar, A.M., Kamireddi, A., Bhalani, S.M., et al. (2009) Clinical Significance of Intramuscular Cysts in the Rotator Cuff and Their Relationship to Full and PartialThickness Rotator cuff Tears. American Journal of Roentgenology, 192, 719-724. https://doi.org/10.2214/AJR.07.3727

[18] Erickson, S.J., Cox, I.H., Hyde, J.S., et al. (1991) Effect of Tendon Orientation of MR Imaging Signal Intensity: A Manifestation of the "Magic Angle" Phenomenon. Radiology, 181, 389-392. https://doi.org/10.1148/radiology.181.2.1924777

[19] Graichen, H., Bonel, H., Stammberger, T., Englmeier, K.H., Reiser, M. and Eckstein, F. (2001) Sex-Specific Differences of Subacromial Space Width during Abduction, with and without Muscular Activity, and Correlation with Anthropometric Variables. Journal of Shoulder and Elbow Surgery, 10, 129-135.

https://doi.org/10.1067/mse.2001.112056

[20] Bakeman, R., Quera, V., McArthur, D. and Robinson, B.F. (1997) Detecting Sequential Patterns and Determining Their Reliability with Fallible Observers. Psychological Methods, 2, 357-370. https://doi.org/10.1037/1082-989X.2.4.357

Submit or recommend next manuscript to OALib Journal and we will provide best service for you:

- Publication frequency: Monthly

- 9 subject areas of science, technology and medicine

- Fair and rigorous peer-review system

- Fast publication process

- Article promotion in various social networking sites (LinkedIn, Facebook, Twitter, etc.)

- Maximum dissemination of your research work

Submit Your Paper Online: Click Here to Submit

Or Contact service@oalib.com 